\title{
Pengaruh Pola Asuh Anak Terhadap Perilaku Menyimpang Pada Usia Remaja
}

\author{
Ridwan Fauzi, Rifqi Roni Chasbulloh, Irfan Yoni Tama
}

Universitas Sebelas Maret

rid199803@gmail.com

\section{Article History}

accepted 24/09/2019

\begin{abstract}
In millennial era like now, we often encounter deviant behavior, the culprits are teenagers. They consider deviant behavior carried out as a natural thing and can even be a pride for the perpetrators. Meanwhile, deviant behavior violates the norms that exist in society. Therefore family parenting is very influential on the process of forming and developing the child's personality, attitudes, and character in the future. Proper parenting in the family can be a strong foundation in building children's behavior so as not to deviate. This study aims to explain the effect of parenting on deviant behavior in adolescence. This study uses the results of studies from journals that are collected and then described and analyzed. The conclusion of this study is that authoritative parenting is ideal because parents are willing to listen and consider the point of view of children so that children with parenting will tend to be responsible and socially competent.
\end{abstract}

Keywords: Deviant Behavior, Parenting, Family

\section{Abstrak}

Era milenial sekarang sering kali kita menjumpai perilaku menyimpang yang pelakunya merupakan kalangan remaja. Mereka menganggap perilaku menyimpang yang dilakukan merupakan suatu hal yang wajar bahkan dapat menjadi suatu kebanggaan bagi pelaku. Sementara itu, perilaku menyimpang melanggar norma-norma yang ada di masyarakat. Oleh karena itu pola asuh keluarga sangat berpengaruh terhadap proses pembentukan dan perkembangan kepribadian, sikap, dan karakter anak di masa mendatang. Pola asuh yang tepat dalam keluarga dapat menjadi pondasi yang kuat dalam membangun perilaku anak agar tidak menyimpang. Penelitian ini bertujuan untuk menjelaskan pengaruh pola asuh anak terhadap perilaku menyimpang pada usia remaja. Kajian ini menggunakan hasil kajian dari jurnal yang terkumpul dan kemudian dideskripsikan dan dianalisis. Kesimpulan kajian ini adalah pola asuh autoritatif menjadi yang ideal karena orang tua bersedia untuk mendengarkan dan mempertimbangkan sudut pandang anak sehingga anak dengan pola asuh ini akan cenderung bertanggung jawab dan berkompeten secara sosial.

Kata kunci: Perilaku menyimpang, Pola asuh, Keluarga

Social, Humanities, and Education Studies (SHEs): Conference Series https://jurnal.uns.ac.id/shes

p-ISSN 2620-9284 e-ISSN 2620-9292 


\section{PENDAHULUAN}

Dewasa ini sering kali kita menemukan penyimpangan sosial yang pelakunya merupakan kalangan remaja. Mereka menganggap penyimpangan sosial yang dilakukan merupakan suatu hal yang wajar bahkan dapat menjadi suatu kebanggaan bagi pelaku. Dari sekian banyak jenis perilaku penyimpangan sosial yang paling sering dilakukan remaja adalah tawuran. Tawuran dianggap sebagi ajang menunjukkan suatu keberanian dirinya namun dalam perilaku yang negatif. Hal tersebut dapat diilihat dari tingginya angka tawuran yang terjadi di kalangan remaja. Menurut KPAI yang dikutip dari tempo.co angka tawuran pelajar meningkat 1,1\% sepanjang tahun $2017-2018$. Pada tahun 2017 angka kasus tawuran yang terjadi hanya 12,9\%, namun di tahun 2018 naik menjadi 14\%. Selain kasus tawuran indikasi yang menunjukkan tingginya penyimpangan sosial yang dilakukan oleh remana yaitu anak berhadapan hukum $(\mathrm{ABH})$. Menurut KPAl yang dikutip dari situs kpai.go.id sepanjang 2011-2017 terdapat 9.266 kasus. Dari tahun ke tahun jumlah paling banyak terdapat pada tahun 2014 silam. Dimana, jumlah kasus ABH mencapai jumlah 2.208, paling tinggi kedua pada 2013 yaitu sebanyak 1.428 kasus, dan tertinggi ketiga pasa 2012 yaitu sebanyak 1.413 kasus.

Salah satu faktor yang menyebabkan terjadinya hal itu ialah pola asuh anak dalam keluarga. Keluarga merupakan pendidik utama yang berperan vital dalam membentuk sikap dan perilaku anak, karena dari merkalah anak mulai menerima pendidikan dasar. Pola asuh anak merupakan segala sesuatu yang dilakukan orangtua untuk membentuk perilaku anak-anak mereka meliputi semua peringatan dan aturan, pengajaran dan perencanaan, contoh dan kasih sayang, serta pujian dan hukuman. Pola asuh anak yang benar akan menghasilkan output sikap yang baik di masa yang akan mendatang, begitu pun sebaliknya pola asuh anak yang buruk akan menghasilkan sikap anak yang buruk di masa depan. Begitu vitalnya pola asuh anak dalam pembentukan karakter anak maka kita sebagai orang tua harus cermat dalam menerapkan pola asuh yang akan di terapkan dalam mendidik anak untuk meminimalisir anak dalam melakukan penyimpangan sosial di kemudian hari.

Setiap orang tua memiliki pola asuh yang berbeda-beda dalam mendidik anak karena setiap orang tua memiliki keinginan yang berbeda-beda berdasaarkan latar belakang mereka. Terdapat orang tua yang ingin anak mereka mengikuti jejaknya sehingga mendidik anak sesuai dengan keinginan mereka, ada juga orang tua yang membebaskan anak mereka untuk berekspresi dan mendukung semua yang dilakukan anaknya, ada juga orang tua yang tidak peduli akan kehidupan anaknya sendiri. Menurut Baumrind (dalam Fitriyani, Listia. 2017) terdapat empat jenis pola asuh yaitu authoritarian, authoritative, permissive, dan penelantaran.

Dari pola asuh yang sudah disebutkan di atas tentu saja memiliki kelebihan dan kekurangan. Pola asuh yang keras akan menyebabkan anak tumbuh dan berkembang menjadi pribadi yang keras dan pada akhirnya dapat menjadi pelaku kekerasan pada temannya. Begitu pula dengan pola asuh yang memberikan kebebasan tanpa ada pengawasan juga dapat menyebabkan anak melakukan perbuatan yang semena-mena tanpa menghiraukan peraturan yang ada.

Anak-anak ibarat bunga yang sedang tumbuh dan berkembang. Bunga yang tumbuh harus di rawat dengan sepenuh hati, disiram dengan air, diberi pupuk, dipagari agar terlindung dari tangan-tangan jahil. Begitu juga dengan anak, kita harus memberikan pola asuh yang tepat di sertai kasih sayang dan perhatian agar anak dapat tumbuh dan berkembang dengan baik.

Tulisan ini mencoba menguraikan pengaruh pola asuh anak terhadap penyimpangan sosial pada usia remaja. 


\section{METODE}

Metode yang digunakan adalah studi kepustakaan, menurut Mardalis dalam (Abdi Mirzaqon T. 2017) mengemukakan bahwa "Studi kepustakaan adalah suatu studi yang digunakan dalam mengumpulkan informasi dan data dengan bantuan berbagai macam material yang ada di perpustakaan seperti dokumen, buku,majalah, kisah-kisah sejarah, dsb". Peneliti melakukan kajian yang berkaitan dengan toeri yang berkaitan dengan topik penelitian, mengumpulkan informasi sebanyak-banyaknya dan kepustakaan yang berhubungan.

\section{A. Perilaku Menyimpang}

\section{HASIL DAN PEMBAHASAN}

Pengertian perilaku menurut Skiner adalah suatu respon atau reaksi individu terhadap stimulus atau rangsangan dari luar pengertian itu dikenal dengan SOR (Stimulus-Organisme-Respon). Perilaku manusia dipengaruhi oleh rangsangan dari luar baik itu secara sengaja maupun tidak disengaja (Jarvis, 2010:23-24). Perilaku menyimpang merupakan hasil dari proses sosialisasi yang tidak sempurna (vivie vike mantiri, 2014). Perilaku menyimpang yang juga biasa dikenal dengan nama penyimpangan sosial adalah perilaku yang tidak sesuai dengan nilai-nilai kesusilaan atau kepatutan, baik dalam sudut pandang kemanusiaan (agama) secara individu maupun pembenarannya sebagai bagian dari pada makhluk social. (Nurlaeliyah, 2017)

Dari pengertian di atas dapat disimpulkan bahwa perilaku menyimpang adalah segala perilaku yang tidak sesuai dengan norma yang berlaku di masyarakat baik dalam sudut pandang agama, hukum, kesusilaan, maupun kesopanan sebagai hasil dari proses sosialisasi yang tidak sempurna.

Berdasarkan jumlah individu yang terlibat, Susanti dan Pambudi Handoyo (2013) menyatakan bentuk perilaku menyimpang dibagi menjadi tiga yaitu pertama penyimpangan individu adalah penyimpangan yang dilakukan sendiri tanpa ada campur tangan orang lain. Kedua Penyimpangan kelompok terjadi apabila perilaku menyimpang dilakukan bersama-sama dalam kelompok tertentu. Ketiga Penyimpangan seperti itu dilakukan oleh suatu golongan sosial yang memiliki organisasi yang rapi, sehingga individu ataupun kelompok didalamnya taat dan tunduk kepada norma golongan dan mengabaikan norma masyarakat yang berlaku.

Dari semua penjelasan di atas dapat disimpulkan bahwa perilaku menyimpang dapat dilakukan oleh semua orang baik secara individu, kelompok, maupun oleh golongan sosial tertentu.

Fhilip Graham dalam Endah Rani Pratiwi (2018: 2) menyebutkan bahwa faktor yang menyebabkan terjadinya perilaku menyimpang dibagi menjadi dua yaitu faktor lingkungan yang didalamnya termasuk lingkungan sekolah, pergaulan dengan teman, keluarga yang tercerai berai, serta pengasuhan dalam keluarga dan yang kedua adalah faktor pribadi.

\section{B. Pola Asuh}

Menurut Euis Sunarti (dalam Fitriyani, Listia. 2017), pola asuh merupakan serangkaian interaksi yang intensif, orangtua mengarahkan anak untuk memiliki kecakapan hidup. Sedangkan menurut Chabib Toha (dalam Fitriany, Upi Ratna. 2018) mengemukakan bahwa pola asuh adalah suatu cara terbaik yang dapat ditempuh orang tua dalam mendidik anak sebagai perwujudan dan rasa tanggungjawab kepada anak. Namun ahli lain memberikan pendapat lain, seperti Bakhul Khair pola asuh orang tua merupakan sistem atau cara pendidikan, pembinaan, yang diberikan orang tua kepada anaknya (Fila Damayanti, 2017).

Atas pengertian diatas dapat disimpulkan bahwa pola asuh adalah interaksi antara orang tua dan anak secara intensif dalam mendidik, membimbing, dan membina anak agar mencapai kedewasaannya sesuai dengan nilai etika dan norma sosial yang ada dalam masyarakat. 
Pola asuh orang tua sangat bervariasi. Menurut Diana Baumrind (dalam Nur Ayu Rifaiyaty, 2011).terbagi menjadi empat macam yaitu:

1. Authoritarian, Gaya asuh yang bersifat membatasi dan menghukum, dimana hanya ada sedikit percakapan antara orang tua dan anak. Anak-anak dari orang tua yang otoriter seringkali berperilaku secara tidak kompeten secara sosial. Mereka cenderung cemas menghadapi situasi sosial, tidak bisa membuat inisiatif dalam berkreativitas, dan memiliki keahlian komunikasi yang buruk.

2. Authoritatif, Gaya asuh positif yang mendorong anak untuk independen namun masih membatasi dan mengontrol tindakan mereka. Pola asuh jenis ini biasa disebut juga pola asuh demokratis.

3. Permissive, Gaya asuh dimana orang tua sangat terlibat dalam kehidupan anaknya tetapi tidak banyak memberi batasan atau kekangan pada perilaku mereka.

4. Penelantaran, Gaya asuh dimana orangtua tidak terlibat aktif dalam kehidupan anaknya, bahkan ketika anaknya menjadi remaja atau masih balita. Anak dari orang tua yang tidak peduli ini menganggap bahwa aspek lain dari kehidupan orang tuanya lebih penting daripada aspek kehidupan anaknya.

\section{Pengaruh Pola Asuh Anak terhadap Perilaku Penyimpangan pada Usia Remaja}

Pola asuh keluarga sangat berpengaruh terhadap proses perkembangan anak. Pola asuh yang tepat dalam keluarga dapat menjadi pondasi yang kuat dalam membangun perilaku anak agar tidak menyimpang. Sesuai dengan Baumrind (2005) pola asuh yang ideal adalah autoritatif (authoritative) dimana orang tua bersedia untuk mendengarkan dan mempertimbangkan sudut pandang anak sehingga anak dengan pola asuh ini akan cenderung mandiri, bertanggung jawab, dan berkompeten secara sosial. Orang tua juga bersikap hangat dan penuh perhatian namun tetap tegas dalam membimbing dan memberi tuntutan dengan mempertimbangkan kemampuan anak sehingga dapat meminimalisir perilaku menyimpang pada anak dimasa mendatang yang diakibatkan oleh proses sosialisasi yang kurang sempurna. Pendapat yang sama juga dikemukakan oleh Hart et all (dalam Burhan Amirudin 2016) dimana ia berpendapat bahwa pengasuhan autoritatif adalah polah asuh yang efektif untuk diterapkan orang tua dalam mendidik anaknya karena beberapa alasan berikut:

1. Orang tua yang autoritatif merupakan keseimbangan yang tepat antara kendali dan otonomi. Sehingga memberi kesempatan anak untuk membentuk kemandirian dan memberikan standar, batas, dan panduan yang dibutuhkan anak.

2. Orang tua yang autoritatif lebih cenderung melibatkan anak dalam kegiatan memberi dan menerima secara verbal dan memperbolehkan anak mengutarakan pandangan mereka.

3. Kehangatan dan keterlibatan orang tua yang diberikan oleh orang tua yang autoritatif membuat anak lebih bisa menerima pengaruh orang tua

Menurut Surya (dalam Lutfia Nur Aini 2011) sifat dan perilaku anak sangat dipengaruhi dengan pola asuh kedua orang tuanya. Terlalu memanjakan atau memandang sebelah mata keberadaan mereka bisa berakibat buruk terhadap kepribadian mereka kelak. Oleh sebab itu, seringkali anak-anak yang tumbuh dan dibesarkan dalam pola asuh yang keliru dan negif ataupun lingkungan yang kurang mendukung cenderung mempunyai konsep diri yang negative, dan sikap positif orang tua akan menimbulkan konsep dan pemikiran yang positif serta sikap menghargai diri sendiri (Qumana. 2008). 
Dari hasil penelitian yang dilakukan Luthfiah Nur Aini (2011), orang tua yang memberikan pola asuh otoriter kepada anaknya lebih banyak melakukan kenakalan dari pada orang tua yang memberikan pola asuh demokratis dan permisif. Dari pola asuh tersebut anak akan senantiasa menuruti orang tua sewaktu dirumah. Dan anak akan melakukan suatu kenakalan diluar rumah, karena anak beranggapan kalau dirinya bebas dan tidak ada yang mengaturnya di luar rumah maka anak akan melakukan suatu perilaku menyimpang (kenakalan remaja).

Diharapkan orangtua dapat mempertimbangkan pola asuh terbaik yang akan diterapkan supaya anak tidak berperilaku menyimpang dikemudian hari. Menerapkan pola asuh yang kurang tepat seperti terlalu mengekang anak dengan menuntut banyak hal tanpa mendengarkan dan melihat kemampuannya dapat membuat anak hanya patuh saat sedang berada di rumah dan melakukan penyimpangan di luar rumah, sedangkan pola asuh yang terlalu membebaskan anak dengan tanpa batasan dapat menyebabkan anak berbuat semaunya tanpa memandang norma-norma yang tersedia.

\section{SIMPULAN}

Perilaku menyimpang adalah segala perilaku yang tidak sesuai dengan norma yang berlaku di masyarakat baik dalam sudut pandang agama, hukum, kesusilaan, maupun kesopanan sebagai hasil dari proses sosialisasi yang tidak sempurna

Pola asuh adalah interaksi antara orang tua dan anak secara intensif dalam mendidik, membimbing, dan membina anak agar mencapai kedewasaannya sesuai dengan nilai etika dan norma sosial yang ada dalam masyarakat.

Berdasarkan pembahasan mengenai perilaku menyimpang dan pola asuh dapat disimpulkan bahwa pola asuh keluarga sangat berpengaruh terhadap proses pembentukan dan perkembangan kepribadian, sikap, dan karakter anak di masa mendatang. Pola asuh autoritatif merupakan pola asuh yang ideal untuk diterapkan orang tua dalam mendidik anaknya agar tidak berperilaku menyimpang pada usia remaja nanti.

\section{DAFTAR PUSTAKA}

Aini, Lutfia Nur. (2011). HUBUNGAN POLA ASUH ORANG TUA DENGAN KENAKALAN REMAJA DI RW V KELURAHAN SIDOKARE KECAMATAN SIDOARJO. Jurnal Keperawatan \& Kebidanan. Diakses dari https://jurnalonline.Ippmdianhusada.ac.id/index.php/jkk/article/view/59/38 tanggal 23 September 2019.

Amirudin, Burhan, 2016. PENGARUH POLA ASUH OTORITATIF TERHADAP KECERDASAN INTERPERSONAL SISWA KELAS V SD NEGERI SEKECAMATAN PUNDONG BANTUL. Universitas Negeri Yogyakarta. Skripsi. Diakses dari http://eprints.uny.ac.id/37886/1/Burhan\%20Aminudin.pdf pada 23 September 2019.

Damayanti, Fila. 2017. PENGARUH POLA ASUH ORANG TUA TERHADAP PERILAKU SOSIAL ANAK DI KELOMPOK B1 TK KEMALA BHAYANGKARI 01 PIM STAF BESUSU TENGAH. Universitas Tadulako. Jurnal Bungamputi. Diakses dari http://jurnal.untad.ac.id/jurnal/index.php/Bungamputi/article/view/8852 pada 23 September 2019.

Fatchurahman. M, Pratikto Herlan. (2012). Kepercayaan Diri, Kematangan Emosi, Pola Asuh Orang Tua Demokratis dan Kenakalan Remaja. Jurnal Psikologi Indonesia. Vol. 1, No. 2: 77-87. Dlakses dari http://jurnal.untagsby.ac.id/index.php/persona/article/view/27 pada 23 September 2019. 
Firmansyah, M Julnis. (2018, September 12). KPAl: Tawuran Pelajar 2018 Lebih Tinggi Dibanding Tahun Lalu.TEMPO.CO. Diakses dari https://metro.tempo.co/read/1125876/kpai-tawuran-pelajar-2018-lebih-tinggidibanding-tahun-lalu/full\&view=ok

Fitriany, Upi Ratna. (2018). HUBUNGAN ANTARA POLA ASUH ORANG TUA DENGAN GAYA BELAJAR SISWA DI KECAMATAN BANDUNG KULON KOTA BANDUNG. Universitas Pasundan Bandung. Skripsi. Diakses dari http://repository.unpas.ac.id/38678/ pada 23 September 2019.

Fitriyani, Listia. (2015). PERAN POLA ASUH ORANG TUA DALAM MENGEMBANGKAN KECERDASAN EMOSI ANAK. Vol. XVIII, No. 1. Diakses dari https://journal.iain-samarinda.ac.id/index.php/lentera journal/article/view/431 pada 23 September 2019.

Jarvis, Matt. (2012). Teori-teori Psikologi. Yogyakarta: Nusamedia.

Mantiri, Vive Vike. (2014). PERILAKU MENYIMPANG DI KALANGAN REMAJA DI KELURAHAN PONDANG, KECAMATAN AMURANG TIMUR KABUPATEN MINAHASA SELATAN. Jurnal Volume III. No 1. Diakses dari https://ejournal.unsrat.ac.id/index.php/index/index pada 23 September 2019.

Nisrina, Siti, dkk. (2016). PEMBINAAN PERILAKU SOSIAL REMAJA PENGHUNI YAYASAN ISLAM MEDIA KASIH KOTA BANDA ACEH. Jurnal IImiah Mahasiswa Pendidikan Kewarganegaraan Unsyiah Volume 1, Nomor 1: 192-204. Diakses dari http://iim.unsyiah.ac.id/pendidikan-kewarganegaraan/article/view/483 pada 23 September 2019.

Nurlaeliyah. (2017). PERILAKU MENYIMPANG REMAJA TERHADAP PERKEMBANGAN JIWA KEAGAMAAN. Jurnal Pendidikan dan Studi Islam Volume $4 . \quad$ Nomor 1.4 Diunduh dari https://jurnal.faiunwir.ac.id/index.php/Jurnal Risalah/article/download/82/42/ pada 23 September 2019.

Pratiwi, Endah Rani. (2018). KONSELING INDIVIDUAL DENGAN TEKNIK BEHAVIORAL UNTUK MENGATASI PERILAKU TIDAK DISIPLIN SISWA KELAS V SD NEGERI O2 TAMBAKBAYA TAHUN PELAJARAN 2017/2018. Skripsi. FKIP Universitas Muhammadiyah Surakarta. Diakses dari http://eprints.ums.ac.id/64357/1/NASKAH\%20PUBLIKASI.pdf pada 23 September 2019.

Rifqiyaty, Nur Ayu. (2011). HUBUNGAN POLA ASUH ORANG TUA TERHADAP PEMECAHAN MASALAH SECARA ANALOGI PADA ANAK KELAS 3 SDIT ALMUGHNI KUNINGAN JAKARTA SELATAN. Diakses dari http://eprints.binus.ac.id/6531/1/2011-2-00010-PL\%20abstrk.pdf tanggal 23 September 2019.

Setyawan, Davit. (2017, Oktober 10). KPAI : Enam Tahun Terakhir, Anak Berhadapan Hukum Mencapai Angka 9.266 Kasus. Berita KPAl. Diakses dari http://www.kpai.go.id/berita/kpai-enam-tahun-terakhir-anak-berhadapan-hukummencapai-angka-9-266-kasus

Susanti, lis dan Handoyo, Pambudi. (2015). PERILAKU MENYIMPANG DIKALANGAN REMAJA PADA MASYARAKAT KARANGMOJO PLANDAAN JOMBANG. Jurnal Paradigma. Volume 03 Nomer $02 . \quad$ Diakses dari https://media.neliti.com/media/publications/251546-perilaku-menyimpangdikalangan-remaja-pa-72979f33.pdf pada 23 September 2019.

T, Abdi Mirzaqon. (2017). STUDI KEPUSTAKAAN MENGENAI LANDASAN TEORI DAN PRAKTIK KONSELING EXPRESSIVE WRITING. Diunduh dari https://media.neliti.com/media/publications/253525-studi-kepustakaan-mengenailandasan-teor-c084d5fa.pdf pada 23 September 2019. 